\title{
Medicinal Plants and Other Living Organisms with Antitumor Potential against Lung Cancer
}

\author{
Luara de Sousa Monteiro, Katherine Xavier Bastos, \\ José Maria Barbosa-Filho, Petrônio Filgueiras de Athayde-Filho, Margareth de Fátima \\ Formiga Melo Diniz, and Marianna Vieira Sobral
}

Department of Pharmaceutical Sciences, Federal University of Paraiba, 58051-900 João Pessoa, PB, Brazil

Correspondence should be addressed to Marianna Vieira Sobral; mariannavbs@gmail.com

Received 23 April 2014; Revised 5 July 2014; Accepted 8 July 2014; Published 24 July 2014

Academic Editor: Thomas Efferth

Copyright (C) 2014 Luara de Sousa Monteiro et al. This is an open access article distributed under the Creative Commons Attribution License, which permits unrestricted use, distribution, and reproduction in any medium, provided the original work is properly cited.

\begin{abstract}
Lung cancer is a disease with high morbidity and mortality rates. As a result, it is often associated with a significant amount of suffering and a general decrease in the quality of life. Herbal medicines are recognized as an attractive approach to lung cancer therapy with little side effects and are a major source of new drugs. The aim of this work was to review the medicinal plants and other living organisms with antitumor potential against lung cancer. The assays were conducted with animals and humans, and Lewis lung carcinoma was the most used experimental model. China, Japan, South Korea, and Ethiopia were the countries that most published studies of species with antitumor activity. Of the 38 plants evaluated, 27 demonstrated antitumor activity. In addition, six other living organisms were cited for antitumor activity against lung cancer. Mechanisms of action, combination with chemotherapeutic drugs, and new technologies to increase activity and reduce the toxicity of the treatment are discussed. This review was based on the NAPRALERT databank, Web of Science, and Chemical Abstracts. This work shows that natural products from plants continue to be a rich source of herbal medicines or biologically active compounds against cancer.
\end{abstract}

\section{Introduction}

Cancer is a collection of heterogeneous genetic diseases united by common alterations in multiple cellular signaling pathways [1]. Various hallmarks have been proposed for cancer cells. Evasion of programmed cell death or apoptosis has been recognized as one of the main alterations that dictate malignant growth [2]. Furthermore, other features include self-sufficiency in growth signaling, deregulation of cellular energetics, sustained angiogenesis, evasion of immune detection, and tissue invasion and metastasis [13]. In addition, two characteristics of cancer that facilitate acquisition of these hallmarks have been described: genome instability and mutation tumor-promoting inflammation [2]. Coordinated processes such as cell proliferation, differentiation, and apoptosis are modified, producing altered cellular phenotypes with these specific characteristics $[1,2]$.
According to the World Health Organization (WHO), cancer represents noncommunicable diseases responsible for $63 \%$ of deaths worldwide, where it is characterized as the second cause of death in western countries $[4,5]$. Its incidence is strongly affected by demographic aspects, such as population aging, eating habits, and, in particular, environmental factors such as exposure to ultraviolet rays. The International Agency for Research on Cancer (IARC) estimates that there were 12.7 million new cancer cases in 2008 and that this number is expected to grow to 21.4 million by $2030[6,7]$.

Lung cancer is currently the malignant tumor with the highest mortality rate worldwide, often because it is not detected until there has been substantial progression of the illness, which leads to a significant reduction in quality of life of the patient [8]. Different factors are pointed out as possible causes of lung cancer, including active cigarette smoking, exposure to secondhand cigarette smoke (passive smoking), 
pipe and cigar smoking, exposure to indoor and outdoor air pollution, exposure to radiation, and occupational exposure to agents such as asbestos, nickel, chromium, and arsenic [9]. The most important risk factor is smoking [10] and the incidence rates of lung cancer are generally higher among men than women [11]. Lung cancer is classified into nonsmall cell lung carcinoma (NSCLC), including squamous cell carcinoma, adenocarcinoma, and large cell carcinoma, which represents $80 \%$ of all lung cancer cases, and the remaining cases are small cell lung carcinoma (SCLC) $[11,12]$. Recently, a new classification was published that defined "molecular subtypes" of lung cancer based on specific actionable genetic aberrations [13]. Many strategies have been studied for lung cancer chemoprevention and treatment, including STAT3 pathway inhibition (e.g., curcumin), cell-cycle arrest (e.g., gambogenic acid), hTERT silencing, miRNA modulation, iNOS suppression, chitin inhibition, angiotensin receptor blockade, TGF- $\beta$ antagonism, VEGFR-2/EGFR inhibition (e.g., vandetanib), and Nrf2 activation [14]. Some strategies have been proven effective in human trials, for example, the use of ceritinib, a new ALK (anaplastic lymphoma kinase gene) inhibitor, in patients with advanced lung cancers harboring genetic alterations in ALK, in a phase 1 study [15]. In addition, the study of tumor-associated biomarkers has grown with the aim of reducing the mortality rate of lung cancer by early diagnosis and prognosis [16]. Another approach that has been studied is the use of the cancer stem cell model, which offers new insights into the limitations of current cancer treatments [17]. New opportunities for targeted therapy are under development based on the discovery of multiple molecular mechanisms underlying the development, progression, and prognosis of lung cancer. Among them, the targeted inhibition of the vascular endothelial growth factor (VEGF) or epidermal growth factor (EGF) signaling pathways has been clinically validated in the treatment of advanced NSCLC [18].

Nowadays, surgery, chemotherapy, radiation, hormones, and immunotherapy are the main approaches for the cancer treatment, often supplemented by other complementary and alternative therapies, such as herbal medicines. Although chemotherapy is the method most used, several problems are associated with its use, including limited efficacy, severe toxicity, and multidrug resistance [19].

Plants have a long history of use in the treatment of cancer and continue to be a major source of new drugs [20]. Herbal medicines have been recognized as one of the attractive approaches for lung cancer therapy because they have proven to be useful and effective in sensitizing conventional agents, prolonging patient survival time, preventing side effects of chemotherapy, and improving quality of life in lung cancer patients [21]. A recent cohort study with 453 cancer patients revealed that the percentage of patients using herbal medicines in combination with conventional chemotherapy was approximately 77\% [22]. In these cases, natural products as complementary therapy for the treatment of lung cancer were used mainly with the aim of reducing toxicity, alleviating cancer-related symptoms, stimulating the immune system, and even having direct anticancer effects [23].
Many natural products or synthetic analogs are still widely used clinically, for example, the so-called vinca alkaloids, vinblastine and vincristine, isolated from the Madagascar periwinkle, Catharanthus roseus, paclitaxel (Taxol), obtained from the leaves of various Taxus species, and the two clinically active agents, etoposide and teniposide, which are semisynthetic derivatives of the natural product epipodophyllotoxin [20]. Other promising agents, natural or synthetic analogs, are in the clinical development phase, including flavopiridol [24] and combretastatin A4 [25]. In addition, many compounds obtained from plants or other living organisms, alone or in combination, are still studied by in vitro models for determining their mechanisms of action against lung cancer cells [26-37].

The most common forms of therapeutic use of plants worldwide are teas and herbal infusions. Considering that their use has increased in recent years aiming to reduce the risks of cardiovascular disease and cancers, research is going on to characterize this effect. Recent data showed that different teas and herbal infusions widely consumed in Hong Kong, Macau, Taiwan, Mainland China, and many other places in the world have antiproliferative effects against human lung cancer cells [38]. Many cancer patients take these medicines, but their effects at the cellular level are largely unknown. However, different preclinical and clinical studies have shown the antitumor activity of herbal extracts against lung cancer [39]. The data have shown that induction of apoptosis is the major mechanism of action of these extracts. The majority of the articles show the effect of Chinese herbal extracts. Some of them show that the response of lung tumor cells to these extracts was similar to their response to conventional chemotherapeutic drugs, and that their mechanism of action was associated with apoptosis induction [40]. Some examples of medicinal herbs with antitumor activity against lung cancer cells can be cited. Selaginella tamariscina is a traditional Chinese herb with antimetastatic effects in vitro and in vivo against lung cancer cells [41]. Crocus sativus L. (Saffron) aqueous extract is widely used as a food additive and in traditional medicine for cancer. Its effects against lung cancer cells were investigated, and antilung cancer activity was associated with induction of apoptosis [31]. The bioactive fraction of Toona sinensis leaves inhibited H441 xenograft tumor growth in both therapeutic and preventive experiments. An in vitro study revealed that the natural product acts by inducing apoptosis [42]. The methanolic fraction of Sesbania grandiflora was found to exert potent antiproliferative effects especially against human lung cancer cell lines. This effect was related to the induction of apoptosis associated with high levels of reactive oxygen species (ROS) intermediates [43]. A study of the combination of active components of Prunella revealed that total triterpenes and total phenols had antilung cancer activity and that their combination significantly enhanced the activity. Thus, its efficacy against lung cancer was attributable to multiple components acting at an optimal ratio [44]. Descurainia sophia has been traditionally used in Korean medicine. Recent data from the study of gene expression profile found the antitumor effect of the ethanol extract of the seeds of $D$. sophia against lung cancer to be involved with 
the regulation of metabolism- and signaling-related pathways [45]. Mountain ginseng butanol extract inhibited lung cancer cell growth by inducing apoptosis. Its mechanisms were associated with a reduction in NF- $\kappa \mathrm{B}$ activity and increase in p53 activity [46].

Substances isolated from various medicinal plants have also been extensively studied for their antilung cancer activity. [6]-Gingerol, a pungent ingredient of ginger (Zingiber officinale) showed antiangiogenic activity in vitro and in vivo and reduced the number of lung metastases in mice receiving B16F10 melanoma cells [47]. Embelin, an active component of fruits of Embelia ribes, has been demonstrated to possess a broad spectrum of therapeutic properties, including antitumor activity against lung cancer cells. Recent data indicate the crucial role of $\mathrm{p} 38$ and JNK pathways in embelininduced apoptosis [48]. Danshen (Salvia miltiorrhiza Bunge) is a traditional medicine that has been used in China to treat various diseases, including cancer. Tanshinone I is a diterpene isolated from this species, which reduced lung adenocarcinoma tumor growth. The studies of its mechanisms showed that the compound inhibits pulmonary tumor formation in an animal model by downregulation of the cell cycle at $S$ and G2/M phases [27]. A carbazole alkaloid isolated from Murraya koenigii Spreng, girinimbine, inhibited lung cancer cell growth by inducing both intrinsic and extrinsic pathways of apoptosis [49]. Capilliposide, extracted from a traditional Chinese medicine, Lysimachia capillipes, induced apoptosis in NSCLC cells. Xenograft tumor growth was significantly decreased after in vivo treatment. The in vitro data revealed that capilliposide increased the intracellular level of ROS, which activated the mitochondrial apoptotic pathway [50]. Scutellaria baicalensis root is used in China as an adjuvant in the chemotherapy of lung cancer. Recently, three compounds were associated with its activity, baicalin, baicalein, and wogonin [51]. Subamolide A, isolated from Cinnamomum subavenium, induced lung cancer cell death by ROS generation, which triggers mitotic catastrophe followed by apoptosis [52]. Terpinen-4-ol, a monoterpene component of the essential oils of several aromatic plants, showed its antitumor effect on NSCLC cells by induction of apoptosis, with involvement of the mitochondrial apoptotic pathway [53]. Davallic acid is the major active compound of Davallia divaricata, a species traditionally employed in folk medicine for the therapy of lung cancer in Taiwan. Recent data showed that this compound induced oxidative stress and apoptosis in lung cancer cells [54]. Total flavonoids of Daphne genkwa inhibited tumor growth and metastasis by protecting the viability of host immunocytes and their proliferation potential and selectively inhibiting tumor cell proliferation. In this fraction, daphnodorin B was the predominant constituent [55].

In addition, many studies have shown the use of combined therapy of herbal medicines or natural substances with chemotherapeutic drugs to enhance their antitumor effects and/or reduce their toxicity. The combination of Xiao-AiPing, a traditional Chinese medicine, and cisplatin promotes the infiltration and function of $\mathrm{CD}^{+} \mathrm{T}$ cells and thus enhances the growth-inhibitory effects of cisplatin on LLC xenografts [56]. Marsdenia tenacissima has long been used as a remedy to treat cancer in China. Its combination with gefitinib, an orally active tyrosine kinase inhibitor, improved gefitinib efficacy in NSCLC regardless of EGFR status $[57,58]$. The combined therapy of plants extracts, Phyllanthus emblica and Terminalia bellerica, with doxorubicin or cisplatin resulted in a synergistic effect and the possibility of reducing the doses of the chemotherapeutic drugs [59]. Fuzheng Fangai pill (FZFA), a traditional Chinese formula, is widely used for cancer treatment. Recent studies showed that FZFA combined with cyclophosphamide (CTX) strongly reduced the growth and metastatic rate of LLC through inhibition of the SOCS/JAK-STAT pathway and inflammatory cytokine responses. In addition, it was observed that the combination had greater activity than CTX alone [60]. Osthole is a natural compound extracted from a number of medicinal plants. The combination of osthole and cisplatin, one of the most active chemotherapeutic agents in lung cancer treatment, resulted in greater efficacy in growth inhibition and apoptosis induction [61]. Meta-analysis of randomized trials showed that Astragalus-based Chinese herbal medicine may increase the effectiveness of platinum-based chemotherapy when combined with chemotherapy [62]. A clinical study showed that the combination of Chinese drugs and conventional chemotherapy in NSCLC patients can enhance short-term therapeutic efficacy in the treatment of NSCLC and prolong patients' median survival time, but it did not find any evident impact on median time to progression [63].

New technologies are in development to enhance the activity and reduce the toxicity of natural products during the research of new therapies. Liposomes may be a promising delivery system for drugs in cancer treatment, including lung cancer [64]. The development of liposome-based cisplatin drug called Lipoplatin was beneficial in reducing the nephrotoxicity of cisplatin, the drug of choice for the treatment of NSCLC. Lipoplatin is anticipated to complete phase III clinical trial testing in 2013 and 2014 [65]. $\beta$-elemene, a sesquiterpene vinyl monomer isolated first from Curcuma wenyujin (Zingiberaceae) rhizome, is present in Chinese herbs and plants. Different studies with this compound have shown efficient antilung cancer activity including inhibiting angiogenesis, inducing tumor cell apoptosis, enhancing radiosensitivity, and favorable chemotherapeutic effects in combination with other anticancer agents. In addition, $\beta$ elemene has only slight side effects. However, the clinical application of $\beta$-elemene was limited by its hydrophobic property, poor stability, and low bioavailability. Phase II clinical trials with $\beta$-elemene are in development, and aiming to improve of its pharmacokinetics new delivery systems are being produced, including liposome-based delivery systems of $\beta$-elemene. The authors emphasize that $\beta$-elemene liposomes will be critical for future clinical applications of $\beta$-elemene in lung cancer treatment [66]. Herbal extracts have also been studied using new technologies. The ethanolic extract of Polygala senega (EEPS) caused apoptosis in lung cancer cell line A549. Its poly-(lactic-co-glycolic) acid (PLGA) nanoparticle-encapsulated form enhanced cellular entry and bioavailability and inhibited the growth of lung cancer cells better than EEPS. The apoptosis of A549 cells was associated with decreased expression of survivin and 
PCNA mRNA and increased expression of caspase- 3 and p53 mRNAs of A549 cells. The authors showed that the formulation of EEPS-loaded PLGA nanoparticles was more effective than EEPS, probably due to more aqueous dispersion after nanoencapsulation, and concluded that the nanoencapsulated ethanolic root extract of $P$. senega may serve as a potential chemopreventive agent against lung cancer [67].

In the course of our continuing search for bioactive natural plant products, we have published reviews on crude plant extracts and plant-derived compounds with potential uses [68-77]. Moreover, our group has also reviewed the medicinal and poisonous plants of Northeast Brazil [78], among others [79-84].

The search was carried out in the Web of Science, Chemical Abstracts, and NAPRALERT (acronym for the University of Illinois Natural Products ALERT service) databanks. The references found in the searches were later consulted. For details on the mechanism-based bioassays utilized for antitumor activity, the original references should be consulted.

\section{Results and Discussion}

Natural products have been increasingly used worldwide to treat various diseases, including cancer. Herbal medicines and phytochemicals can be potent agents for lung cancer chemoprevention and treatment by regulating multimolecular targets involved in angiogenesis, metastasis, and severe side effects; only provided quality control and reproducibility issues are solved [21]. Compared with the conventional drugs used in cancer treatment, the toxicity of medicinal plants may seem trivial; however, it is a serious public health problem. Several medicinal plants are considered toxic and can cause serious damage to the health of patients. Therefore, the assessment of the toxicity of medicinal plants, as well as their herbal preparations, is essential to determine the applicability of the sample as a pharmacological drug [85].

In the current review, we present medicinal plants, distributed in diverse parts of the world, with antitumor activity against different in vivo lung cancer models (Table 1). The effectiveness of the medicinal plants depended on the type of drug studied and the bioassay model. Thus, it was possible to classify the extracts as active or inactive, and the mechanisms of action studied were discussed.

Celastraceae was the most cited family for antitumor activity in lung cancer models, followed by Araliaceae, Euphorbiaceae, and Fabaceae. Maytenus serrata was the only species studied of the family Celastraceae, showing antitumor activity for its fruit, root, and stem wood. Eleutherococcus senticosus and Panax ginseng red type were the evaluated species of the family Araliaceae. Among the four mentioned for $P$. ginseng red type, one of the studies showed the antitumor activity of this species against lung adenoma induced by different carcinogenic agents. Studies with $P$. ginseng were carried out with the ethanol-insoluble fraction, obtained from the fractionated water extract. The tumor was induced by a single subcutaneous (s.c.) injection of benzo $[\alpha]$ pyrene (BP), and the treatment with $P$. ginseng significantly inhibited lung tumor incidence. The investigation of the mechanisms of action showed proliferation of splenocytes and generation of activated killer cells in vitro, suggesting immunomodulatory effects [86].

Euphorbia esula, Euphorbia fischeriana, Euphorbia ingens, and Croton macrostachys were the most studied Euphorbiaceae species. All of them showed significant antitumor activity against lung cancer models. Crotepoxide, a novel cyclohexane diepoxide obtained from C. macrostachys and alcoholic extracts of the fruits of this species, inhibited the growth of LLC in mice [87].

Among the active species of the family Fabaceae, Sophora flavescens and Cassia garrettiana were cited. The methanol extract of C. garrettiana was found to contain the substances identified as cassigarol $\mathrm{A}$ and piceatannol. The extract and isolated substances inhibited tumor growth and metastasis in LLC-bearing mice. In addition, cassigarol A and piceatannol inhibited plasmin activity and the formation of capillarylike networks of human umbilical vein endothelial cells (HUVECs), suggesting that the effects of cassigarol A could be due to the inhibition of plasmin activity and formation of tubes (angiogenesis) from HUVECs [88, 89].

Viva-Natural, a natural product extracted from the dietary seaweed Undaria pinnantifida (Alariaceae), demonstrated therapeutic activity and moderate prophylactic activity against LLC in allogeneic mice. This product enhanced the natural cytolytic activity of peritoneal macrophages against $\mathrm{KB}$ cells as targets in an in vitro assay. The data therefore suggest that the antitumor effect of Viva-Natural may be indirect through the activation of nonspecific immune systems [90]. The antitumor potential against LLC has been evaluated in comparison with standard synthetic immunomodulators. The effect of Viva-Natural has been found to be superior to that of isoprinosine but inferior to that of MVE-2 (pyran copolymer) [91]. The combination therapy of VivaNatural and standard anticancer drugs was additively or synergistically effective [90]. Cisplatin, 5-fluorouracil, and vincristine at low doses that were not effective when given alone, manifested antitumor activity when combined with the polysaccharide fraction of Viva-Natural, against implanted LLC (intraperitoneal, i.p.) in syngeneic mice. However, an additional effect on the immune system was not observed when the polysaccharide fraction of Viva-Natural was combined with the anticancer drugs at low doses. Thus, the mechanism of action of the beneficial combination is not yet clear [92].

Brucea javanica (Simaroubaceae) showed the anticarcinoma effect against brain metastasis as a complication of lung cancer. The results of this study showed that the median survival duration (15 months in the treatment group versus 10 months in the control group) and the quality of life of the patients in the combination of radiotherapy and intravenous (i.v.) injection of $10 \%$ Brucea javanica emulsion was much better than in the radiotherapy alone group (control). The results suggest that the $B$. javanica emulsion treatment group exhibited a synergistic action with radiotherapy in the treatment of brain metastasis as a complication of lung cancer [93]. Another study with this herbal extract showed that the preoperative i.v. emulsion of $10 \%$ B. javanica oil may improve surgical treatment of NSCLC [94]. 


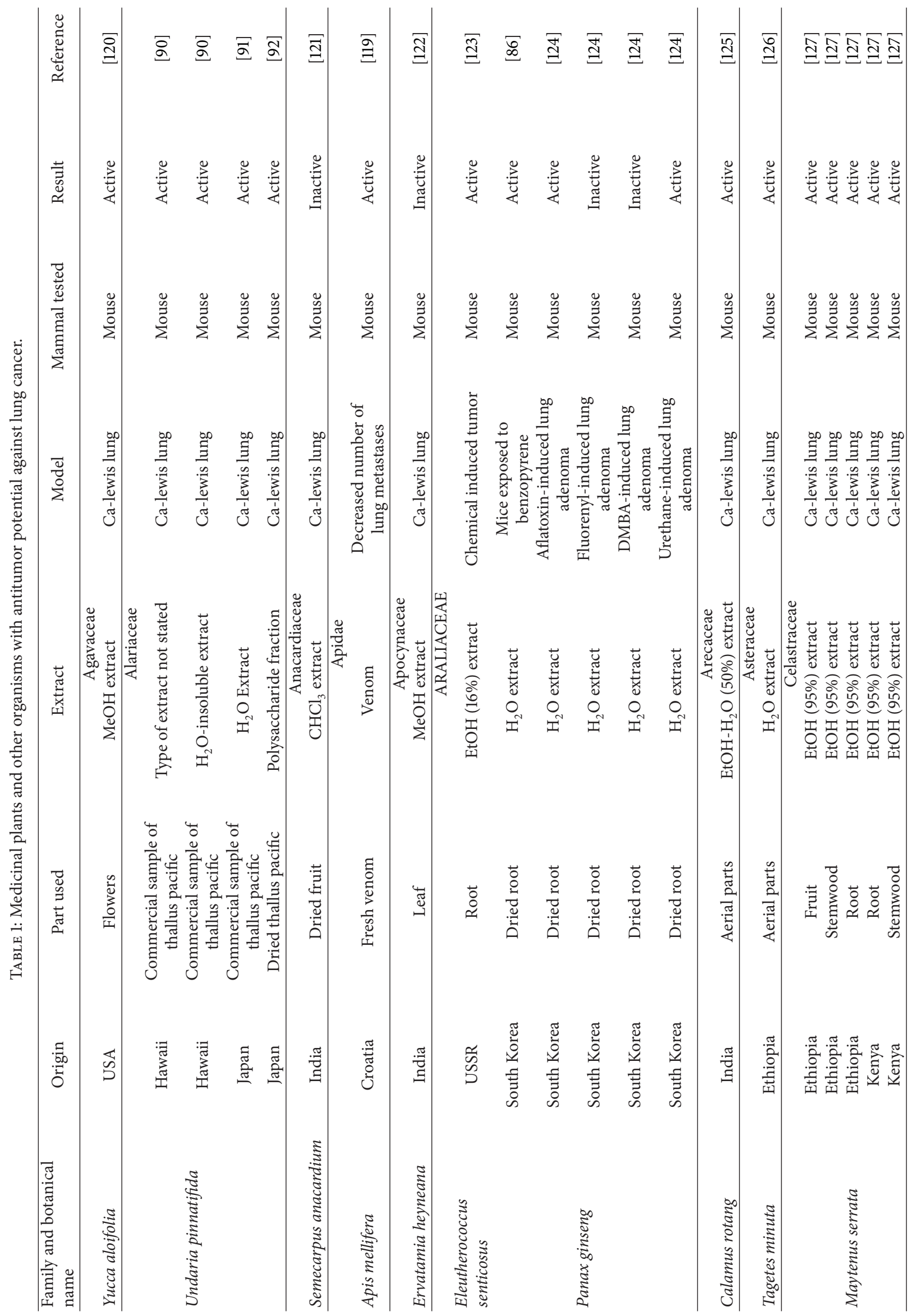




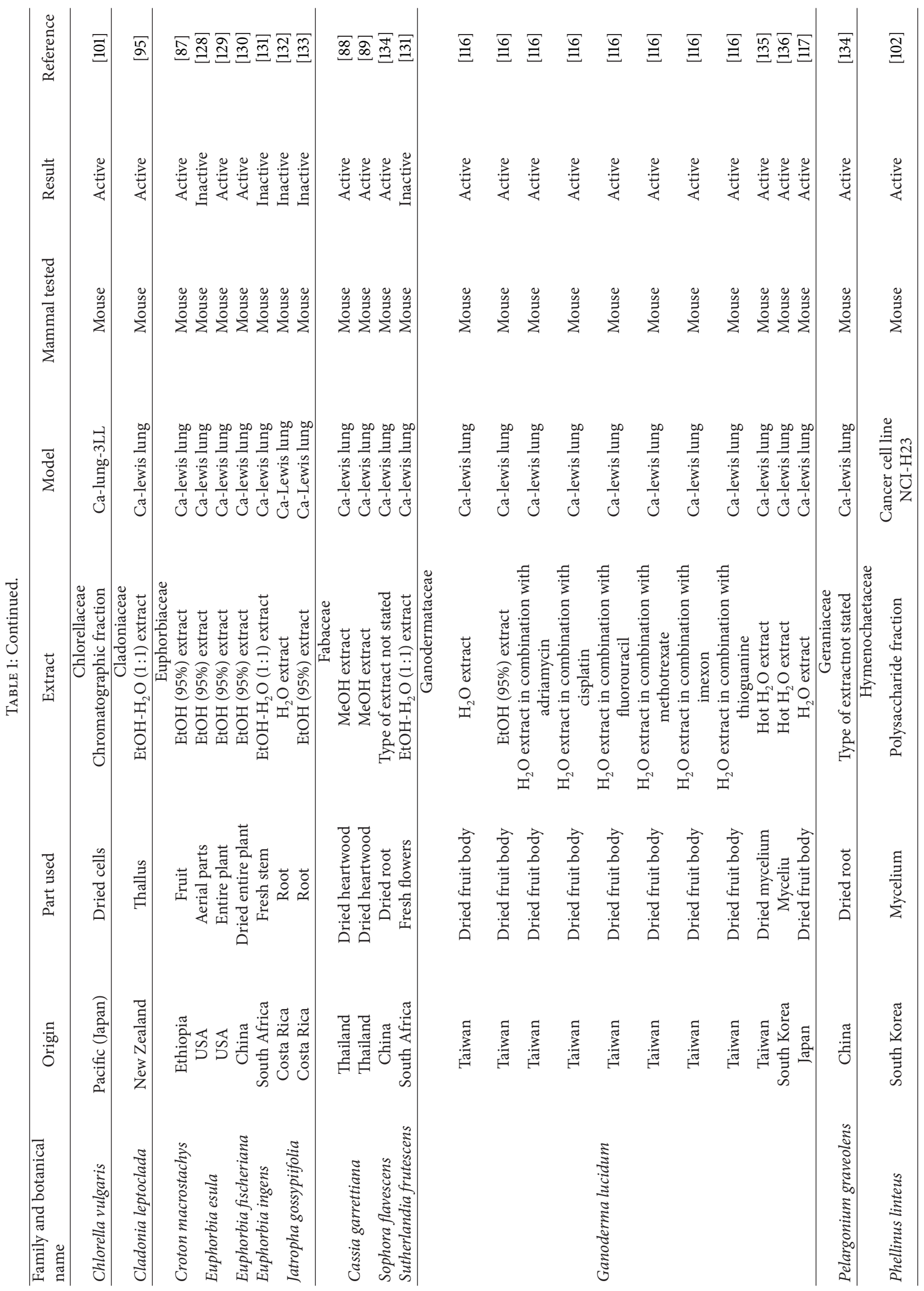




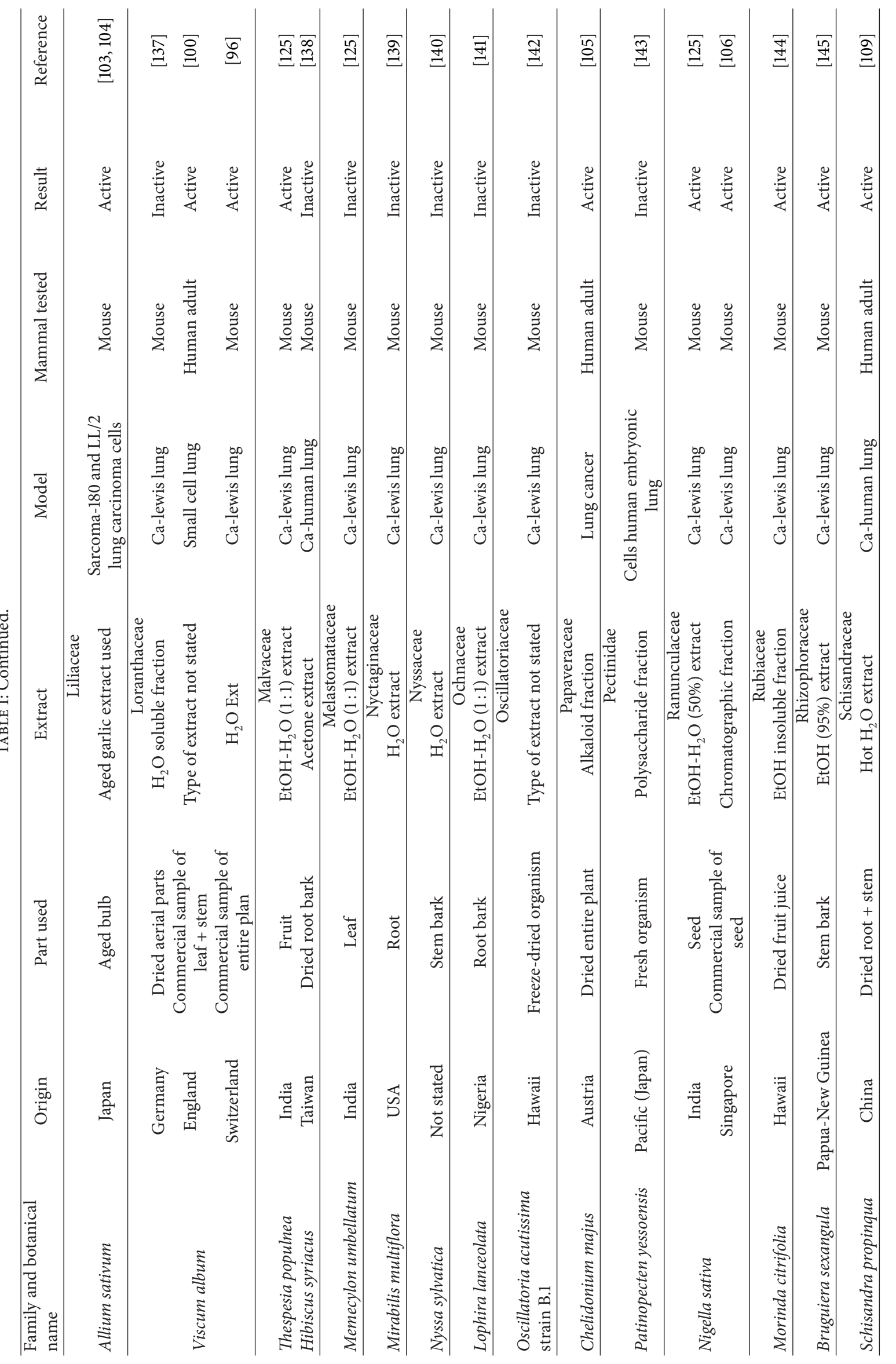




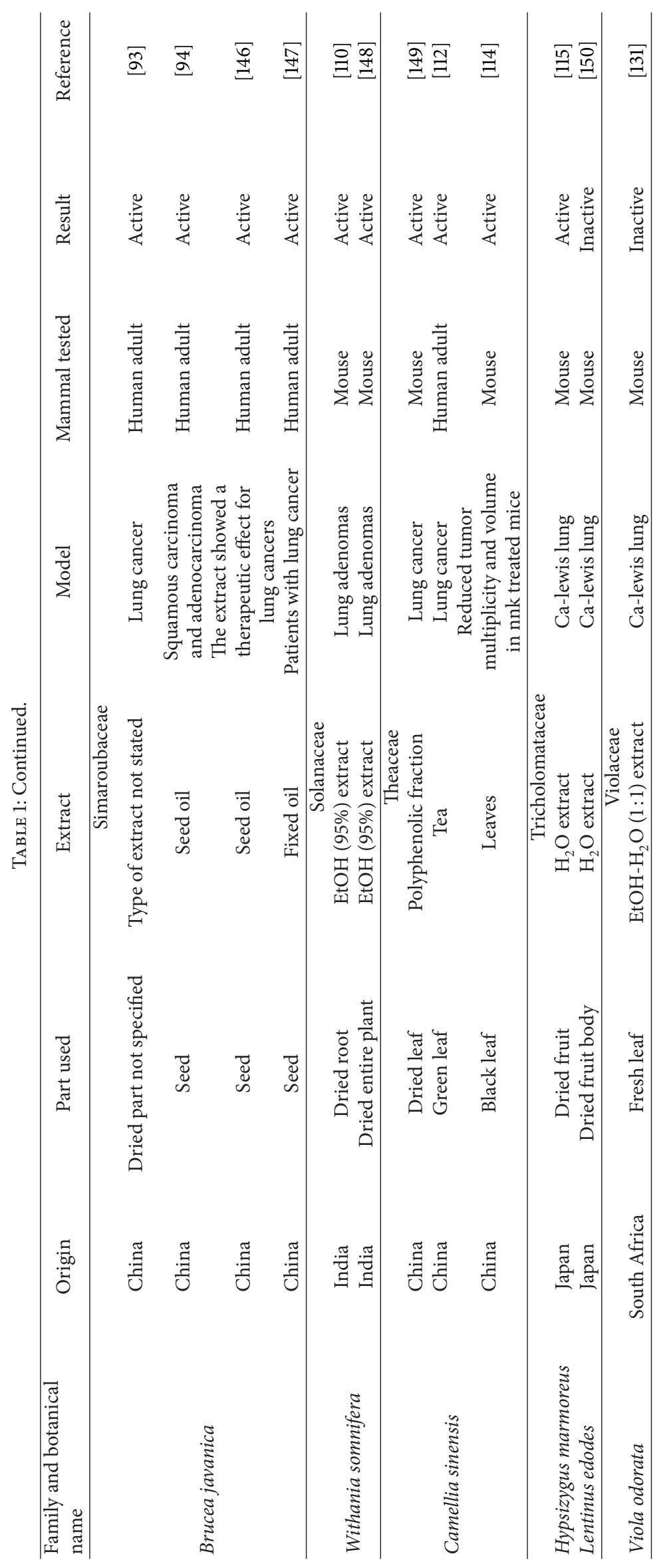


The extract of the lichen Cladonia leptoclada showed significant inhibitory activity against LLC in mice. In this study, an active extract was fractionated, and the principal tumorinhibitory constituent was characterized and identified as 1usnic acid [95].

Extracts of mistletoe (commercial sample of Viscum album leaf and stem) have been used for medicinal purposes for several centuries and are known to contain alkaloids with cytotoxic effects in vitro and in vivo [96]. The administration of mistletoe induced tumor growth inhibition and reduction of metastases, associated with immunomodulation. The authors reported that although lectins represent a class of active components studied of mistletoe origin, it is not likely that they alone are responsible for all effects of the plant extracts $[97,98]$. A randomized phase II study of mistletoe combined with carboplatin-containing regimens was conducted in advanced NSCLC patients. No effects on quality of life or total adverse events were seen. Nevertheless, chemotherapy dose reductions, severe nonhaematological side effects, and hospitalizations were less frequent in patients treated with mistletoe, warranting further investigation as a modifier of chemotherapy-related toxicity [99]. In another study, a patient with SCLS was treated initially with extracts of mistletoe and homoeopathic treatment and appeared to respond. Subsequently, radiotherapy was given and the patient lived for five years and seven months [100]. According to the authors, the acknowledgment of the Viscum album extract as a phytotherapeutic adjuvant may lead to its use together with other treatments in advanced cancer biotherapy $[97,98]$.

Different fractions derived from the unicellular green alga Chlorella vulgaris, strain CK22, were tested in relation to antitumor activity against lung cancer. The most active fraction consisted of galactose-rich carbohydrate (56.1\%) and protein $(36.3 \%)$, suggesting that the protein moiety of the glycoprotein is mainly related to the expression of antilung cancer activity [101].

A study with Phellinus linteus showed that the polysaccharide fraction inhibited tumor growth in NCI-H23-implanted mice and reduced the frequency of pulmonary metastasis of B16F10 melanoma. Also studied was combination therapy with the polysaccharide fraction and Adriamycin. Although the combination was more effective in inhibiting tumor growth, this effect was not observed on the metastases [102].

Garlic (Allium sativum) is a common plant used mainly as a food, and it is a medicinal herb commonly used worldwide. The aged garlic extract (AGE) inhibited the growth of LL/2 lung carcinoma (syngeneic) cells transplanted into mice. AGE stimulated the proliferation of mouse spleen cells and the release of cytokines, increased NK activities, and enhanced phagocytosis by peritoneal macrophages. AGE treatment also stimulated the reactivity of lymphocytes in response to cytokines or mitogens. Therefore, it was observed that the immunostimulant effect was associated with antitumor activity $[103,104]$.

A clinical assay showed that treatment with Chelidonium majus (preparation Ukrain) in nine men with histologically proven lung cancer, previously untreated, induced an increase in the proportion of total T-cells and a significant decrease in the percentage of T-suppressor cells. The restoration of cellular immunity was accompanied by an improvement in the clinical course of the disease. This effect was particularly pronounced in patients who responded to further chemotherapy. The authors concluded that Ukrain can be immunologically effective in lung cancer patients and can improve cellular immune response [105].

The in vivo antitumor effect of a fraction of an ethanolic extract of Nigella sativa seeds was studied on LLC-implanted (s.c.) mice. This fraction prolonged the life span of the mice and produced significant tumor inhibition. Alpha-hederin, a triterpene saponin, was obtained from this fraction, which induced significant dose-dependent tumor inhibition, suggesting that the activity is related to the presence of this compound. However, the underlying mechanism(s) of antitumor activity of alpha-hederin remains to be established [106].

The stems and roots of Schisandra propinqua are a major component of the Manshanxiang Complex, a herbal medicine preparation used for the treatment of lung carcinoma in several hospitals of Yunnan Province in China [107]. In addition, the water extract from the stems and roots of $S$. propinqua shows activity against LLC in animal tests [108]. The triterpenoid manwuweizic acid, isolated from its alcoholic extract, exhibited significant inhibitory activity against LLC, suggesting that this compound is probably a major anticancer active principle of the plant $[108,109]$.

Review articles about the chemical properties, therapeutic benefits, and toxicity of Withania somnifera (ashwagandha, WS), one of the most important herbs of Ayurveda (the traditional system of medicine in India), have been published. The antitumor activity was described in different in vitro and in vivo experimental models, including urethaneinduced lung adenoma in mice. The data showed that the ethanol extract of $W$. somnifera significantly reduced tumor incidence. In addition to providing protection from carcinogenic effects, the treatment also reversed the adverse effects of urethane on total leukocyte count, lymphocyte count, body weight, and mortality $[110,111]$.

Current studies have demonstrated that green tea polyphenols, obtained from Camellia sinensis, are powerful antioxidants with anticarcinogenic properties. The primary catechins in green tea are epicatechin, epicatechin-3-gallate, epigallocatechin, and epigallocatechin-3-gallate. A clinical study investigated the chemopreventive effects of green tea and coffee among cigarette smokers. The results suggest that green tea polyphenols may have an anitmutagenic effect against smoke-induced mutations in humans by blocking the cigarette-induced increase in sister-chromatid exchange frequency. It has also been shown that cultured human lung cells (A549) pretreated with green tea polyphenols and then exposed to a cigarette smoke solution or $\mathrm{H}_{2} \mathrm{O}_{2}$ had a reduced incidence of DNA strand breaks. Pretreatment with green tea polyphenols also reduced the overall toxicity of $\mathrm{H}_{2} \mathrm{O}_{2}$ as determined by cell growth after exposure. These results suggest that green tea polyphenols may inhibit DNA damage and other mutations in cells exposed to oxidants and that this effect is associated with anticarcinogenic properties [112]. A recent article published evidence from epidemiologic studies on cancer prevention by green tea. Various epidemiologic 
studies have examined the association between green tea consumption and lung cancer risk. The inconsistent results of those studies could be partly a result of the potential confounding effect of smoking. The data revealed that the protective effect of green tea consumption on lung cancer risk was confined to nonsmokers [113].

The effects of black tea obtained from C. sinensis were also studied. The administration of black tea polyphenols through the drinking water significantly inhibited 4-(methylnitrosamino)-1-(3-pyridyl)-l-butanone (NNK) and induced early bronchial cell proliferation in the shortterm model. In long-term studies, administration of black tea, after a single dose of $\mathrm{NNK}$, inhibited the progression of adenoma to adenocarcinoma. The cell proliferation rate in adenomas was also suppressed by black tea treatment. The authors related that such activities, at the early and late stages of lung tumorigenesis, may be important for the cancer-chemopreventive activities of black tea [114].

The antitumor activity of Hypsizigus marmoreus, an edible mushroom, was investigated against syngeneic tumor, LLC. H. marmoreus increased the life span, inhibited the activity of spontaneous tumor metastasis, and decreased the number of metastatic nodules. These effects were observed only after i.p. administration, but not as much by oral administration, and the data showed increased immune activity by competent cells [115].

Among the other living organisms with antitumor activity against lung cancer, Ganoderma luncidum (a medicinal fungus) was the most studied and has been used traditionally for the prevention and treatment of cancers for a long time in traditional Chinese medicine [37]. In this review, there were eleven reports describing the species G. lucidum (Ganodermataceae), where eight of them investigated the combination of $G$. lucidum extracts with antineoplastic drugs. This study showed that an aqueous extract of G. lucidum, called "Ling-Zhi or holy mushroom" in traditional Chinese medicine, significantly increased the life span of LLCimplanted syngeneic C57BL/6 mice, when administered i.p. alone or in combination with cytotoxic antitumor drugs (Adriamycin, fluorouracil, thioguanine, methotrexate, and cisplatin) or a synthetic immunomodulator (Imexon) [116]. In another study, the authors suggested that the antitumor and antimetastatic activities of the triterpenoid fraction of G. lucidum against LLC-implanted mice may be due to the inhibition of tumor-induced angiogenesis. The compound identified as ganoderic acid $\mathrm{F}$ was obtained from the acidic fraction of the triterpenoid fraction of the fruit bodies of $G$. lucidum as an active substance that inhibited the angiogenesis [117]. Recent data showed that triterpenes of G. lucidum have antilung cancer activity in vitro and in vivo via enhancement of immunomodulation and induction of cell apoptosis [37]. In addition, G. tsugae, another well-cultivated species of Ganoderma, was evaluated against lung cancer cells. The results revealed that the natural product inhibited the viability of $\mathrm{H} 23 / 0.3$ cells (doxorubicin-resistant lung adenocarcinoma) in vitro and in vivo and enhanced the growth-suppressive effect of doxorubicin on $\mathrm{H} 23 / 0.3$ cells. This effect is associated with the downregulation of the PI3K/Akt signaling pathway. The authors suggest that G. tsugae may be a useful adjuvant therapeutic agent in the treatment of lung cancer [118].

To evaluate the effect of the bee venom on the tumor growth and metastasis formation, a transplantable mammary carcinoma (MCA) was used in the syngeneic CBA mouse. The results showed that the bee venom suppressed the tumor growth and prolonged the survival of the animals compared to the controls, after s.c. or i.v. administration. However, the antimetastatic activity was observed only after i.v. administration, indicating that the antitumor effect of the bee venom could be highly dependent on the route of injection [119].

Considering all the countries covered in the present study, China, Japan, South Korea, and Ethiopia were those that published the most studies of species with antitumor activity against lung cancer: ten works from China, eight works from Japan, and four publications from South Korea and Ethiopia each. The most used cell model for the investigation of antitumor activity against lung cancer was LLC. Of the 58 studies that showed this cell line as the experimental model used, 44 showed its sensitivity to the samples tested. Those data indicated that this cell line is the most used model worldwide to evaluate the antitumor activity in lung cancer cells. Other models cited in few studies included NSCLC and adenomas.

\section{Conclusions}

Several countries have studied medicinal plants with antitumor potential, including against lung cancer. Because many species are active in different experimental models, the natural products from plants continue to be a rich source of herbal medicines or biologically active compounds. There is a need for further studies on the standardization or chemical characterization of the extracts used. With respect to pharmacological studies, most of them were performed in mice. However, there were also studies with humans for various species of plants. This review shows that many medicinal herbs have been examined for antilung cancer activity, presenting important results that provide insight into their use for the treatment of cancer. However, despite many studies showing the evaluation of possible mechanisms of action of these compounds, the majority of studies still presented only preliminary screening data and therefore did not describe any mechanism of action. For these studies, they are classified only as "active." In addition, new research findings have shown extracts as potential phytotherapeutic adjuvants in advanced lung cancer therapy. This could lead to greater safety and benefits for people, contributing to a better access to health care and thereby a better quality of life of patients with lung cancer.

\section{Conflict of Interests}

The authors declare no conflict of interests. 


\section{Acknowledgments}

The authors thank the University of Illinois at Chicago, USA, for the use of the NAPRALERT database for this study and A. Leyva for the English revision of the paper. Thanks are in order also for the financial support provided by CAPES/CNPq/PRONEX-FAPESQ.

\section{References}

[1] J. Luo, N. L. Solimini, and S. J. Elledge, "Principles of cancer therapy: Oncogene and non-oncogene addiction," Cell, vol. 136, no. 5, pp. 823-837, 2009.

[2] D. Hanahan and R. A. Weinberg, "Hallmarks of cancer: the next generation," Cell, vol. 144, no. 5, pp. 646-674, 2011.

[3] D. Hanahan and R. A. Weinberg, "The hallmarks of cancer," Cell, vol. 100, no. 1, pp. 57-70, 2000.

[4] K. Kashfi, "Dysfunctional cell signaling dynamics in oncology: diagnostic, prognostic and treatment opportunities," Biochemical Pharmacology, vol. 85, no. 5, pp. 595-596, 2013.

[5] A. Alwan, D. R. MacLean, L. M. Riley et al., "Monitoring and surveillance of chronic non-communicable diseases: progress and capacity in high-burden countries," The Lancet, vol. 376, no. 9755, pp. 1861-1868, 2010.

[6] J. Ferlay, D. M. Parkin, and E. Steliarova-Foucher, "Estimates of cancer incidence and mortality in Europe in 2008," European Journal of Cancer, vol. 46, no. 4, pp. 765-781, 2010.

[7] IARC, Cancer Incidence and Mortality Worldwide. Cancer Base, International Agency for Research on Cancer, 2011.

[8] D. W. Ford, K. A. Koch, D. E. Ray, and P. A. Selecky, "Palliative and end-of-life care in lung cancer," Chest, vol. 143, no. 5, pp. e498S-e512S, 2013.

[9] A. J. Alberg, M. V. Brock, J. G. Ford, J. M. Samet, and S. D. Spivack, "Epidemiology of lung cancer: Diagnosis and management of lung cancer, 3rd ed: American college of chest physicians evidence-based clinical practice guidelines," Chest, vol. 143, no. 5, pp. 1-29, 2013.

[10] W. N. Rom, J. G. Hay, T. C. Lee, Y. Jiang, and K.-M. TchouWong, "Molecular and genetic aspects of lung cancer," American Journal of Respiratory and Critical Care Medicine, vol. 161, no. 4, pp. 1355-1367, 2000.

[11] R. L. M. Duarte and M. E. M. Paschoal, "Marcadores moleculares no câncer de pulmão: papel prognóstico e sua relação com o tabagismo," Jornal Brasileiro de Pneumologia, vol. 32, no. 1, pp. 56-65, 2005.

[12] A. Jemal, T. Murray, E. Ward et al., "Cancer statistics, 2005," CA: A Cancer Journal for Clinicians, vol. 55, no. 1, pp. 10-30, 2005.

[13] L. West, S. J. Vidwans, N. P. Campbell et al., "A novel classification of lung cancer into molecular subtypes," PLoS ONE, vol. 7, no. 2, Article ID e31906, 2012.

[14] A. K. Greenberg, J. Tsay, K. Tchou-Wong, A. Jorgensen, and W. N. Rom, "Chemoprevention of lung cancer: prospects and disappointments in human clinical trials," Cancers, vol. 5, no. 1, pp. 131-148, 2013.

[15] A. T. Shaw, D.-W. Kim, R. Mehra et al., "Ceritinib in ALKrearranged non-small-cell lung cancer," The New England Journal of Medicine, vol. 370, pp. 1189-1197, 2014.

[16] Y. Zhang, D. Yang, L. Weng, and L. Wang, "Early lung cancer diagnosis by biosensors," International Journal of Molecular Sciences, vol. 14, no. 8, pp. 15479-15509, 2013.
[17] R. M. Reddy, M. Kakarala, and M. S. Wicha, "Clinical trial design for testing the stem cell model for the prevention and treatment of cancer," Cancers, vol. 3, no. 2, pp. 2696-2708, 2011.

[18] M. Méndez, A. Custodio, and M. Provencio, "New molecular targeted therapies for advanced non-small-cell lung cancer," Journal of Thoracic Disease, vol. 3, no. 1, pp. 30-56, 2011.

[19] W. Tan, J. Lu, M. Huang et al., "Anti-cancer natural products isolated from chinese medicinal herbs," Chinese Medicine, vol. 6, no. 1, article 27, pp. 1-15, 2011.

[20] G. M. Cragg and D. J. Newman, "Natural products: a continuing source of novel drug leads," Biochimica et Biophysica ActaGeneral Subjects, vol. 1830, no. 6, pp. 3670-3695, 2013.

[21] S. Jeong, W. Koh, B. Kim, and S. Kim, "Are there new therapeutic options for treating lung cancer based on herbal medicines and their metabolites?" Journal of Ethnopharmacology, vol. 138, no. 3, pp. 652-661, 2011.

[22] M. A. Richardson and J. D. White, "Complementary/alternative medicine and cancer research: a national initiative," Cancer Practice, vol. 8, no. 1, pp. 45-48, 2000.

[23] B. Gerber, C. Scholz, T. Reimer, V. Briese, and W. Janni, "Complementary and alternative therapeutic approaches in patients with early breast cancer: a systematic review," Breast Cancer Research and Treatment, vol. 95, no. 3, pp. 199-209, 2006.

[24] H. H. Sedlacek, "Mechanisms of action of flavopiridol," Critical Reviews in Oncology/Hematology, vol. 38, no. 2, pp. 139-170, 2001.

[25] S. Kapoor, "Combretastatin A4 and its emerging antineoplastic effects," Surgery, vol. 153, no. 6, p. 881, 2013.

[26] C.-T. Yeh, C.-L. Su, C.-Y. F. Huang et al., "A preclinical evaluation of antimycin a as a potential antilung cancer stem cell agent," Evidence-Based Complementary and Alternative Medicine, vol. 2013, Article ID 910451, 13 pages, 2013.

[27] Y.-T. Tung, H.-L. Chen, C.-Y. Lee et al., "Active component of Danshen (Salvia miltiorrhiza Bunge), Tanshinone I, attenuates lung tumorigenesis via inhibitions of VEGF, Cyclin A, and Cyclin B expressions," Evidence-Based Complementary and Alternative Medicine, vol. 2013, Article ID 319247, 10 pages, 2013.

[28] S. Mohan, S. I. Abdelwahab, S. Cheah et al., "Apoptosis effect of girinimbine isolated from Murraya koenigii on lung cancer cells in vitro," Evidence-Based Complementary and Alternative Medicine, vol. 2013, Article ID 689865, 12 pages, 2013.

[29] X. Kang, Z. Xu, Y. Gong et al., "Bufalin reverses HGF-induced resistance to EGFR-TKIs in EGFR mutant lung cancer cells via blockage of Met/PI3k/Akt Pathway and induction of apoptosis," Evidence-Based Complementary and Alternative Medicine, vol. 2013, Article ID 243859, 9 pages, 2013.

[30] Z.-H. Fei, K. Wu, Y.-L. Chen, B. Wang, S.-R. Zhang, and S.-L. $\mathrm{Ma}$, "Capilliposide isolated from Lysimachia capillipes hemsl. Induces ROS generation, cell cycle arrest, and apoptosis in human nonsmall cell lung cancer cell lines," Evidence-Based Complementary and Alternative Medicine, vol. 2014, Article ID 497456, 11 pages, 2014.

[31] S. Samarghandian, A. Borji, S. K. Farahmand, R. Afshari, and S. Davoodi, "Crocus sativus L. (Saffron) stigma aqueous extract induces apoptosis in alveolar human lung cancer cells through caspase-dependent pathways activation," BioMed Research International, vol. 2013, Article ID 417928, 12 pages, 2013.

[32] C.-C. Wu, T.-H. Chen, B.-L. Liu et al., "Destruxin B isolated from entomopathogenic fungus Metarhizium anisopliae induces apoptosis via a Bcl-2 family-dependent mitochondrial 
pathway in human nonsmall cell lung cancer cells," EvidenceBased Complementary and Alternative Medicine, vol. 2013, Article ID 548929, 11 pages, 2013.

[33] B. Y. Kim, J. Lee, S. J. Park, O. S. Bang, and N. S. Kim, "Gene expression profile of the A549 human non-small cell lung carcinoma cell line following treatment with the seeds of descurainia sophia, a potential anticancer drug," EvidenceBased Complementary and Alternative Medicine, vol. 2013, Article ID 584604, 13 pages, 2013.

[34] S. Rupachandra and D. V. L. Sarada, "Induction of apoptotic effects of antiproliferative protein from the seeds of borreria hispida on lung cancer (A549) and cervical cancer (HeLa) cell lines," BioMed Research International, vol. 2014, Article ID 179836, 8 pages, 2014.

[35] A. Kowitdamrong, P. Chanvorachote, B. Sritularak, and V. Pongrakhananon, "Moscatilin inhibits lung cancer cell motility and invasion via suppression of endogenous reactive oxygen species," BioMed Research International, vol. 2013, Article ID 765894, 11 pages, 2013.

[36] P. Narrima, M. Paydar, C. Y. Looi et al., "Persea Declinata (Bl.) Kosterm Bark crude extract induces apoptosis in MCF7 cells via $G_{0} / G_{1}$ cell cycle arrest, Bcl-2/Bax/Bcl-xl signaling pathways and ROS generation," Evidence-Based Complementary and Alternative Medicine, vol. 2014, Article ID 248103, 14 pages, 2014.

[37] Y.-H. Yu, H.-P. Kuo, H.-H. Hsieh et al., "Ganoderma tsugae induces $\mathrm{S}$ phase arrest and apoptosis in doxorubicin-resistant lung adenocarcinoma $\mathrm{H} 23 / 0.3$ cells via modulation of the PI3K/Akt signaling pathway," Evidence-based Complementary and Alternative Medicine, vol. 2012, Article ID 371286, 13 pages, 2012.

[38] F. Li, S. Li, H.-B. Li, G.-F. Deng, W.-H. Ling, and X.-R. Xu, "Antiproliferative activities of tea and herbal infusions," Food \& Function, vol. 4, no. 4, pp. 530-538, 2013.

[39] C. Kaewpiboon, K. Lirdprapamongkol, C. Srisomsap et al., "Studies of the in vitro cytotoxic, antioxidant, lipase inhibitory and antimicrobial activities of selected Thai medicinal plants," BMC Complementary and Alternative Medicine, vol. 12, article 217, 2012.

[40] D. Sadava, J. Ahn, M. Zhan, M.-L. Pang, J. Ding, and S. E. Kane, "Effects of four Chinese herbal extracts on drug-sensitive and multidrug-resistant small-cell lung carcinoma cells," Cancer Chemotherapy and Pharmacology, vol. 49, no. 4, pp. 261-266, 2002.

[41] S. F. Yang, S. C. Chu, S. J. Liu, Y. C. Chen, Y. Z. Chang, and Y. S. Hsieh, "Antimetastatic activities of Selaginella tamariscina (Beauv.) on lung cancer cells in vitroand in vivo," Journal of Ethnopharmacology, vol. 110, no. 3, pp. 483-489, 2007.

[42] C. Yang, Y. Huang, C. Wang et al., "Antiproliferative and antitumorigenic activity of Toona sinensis leaf extracts in lung adenocarcinoma," Journal of Medicinal Food, vol. 13, no. 1, pp. 54-61, 2010.

[43] S. Pajaniradje, K. Mohankumar, R. Pamidimukkala, S. Subramanian, and R. Rajagopalan, "Antiproliferative and apoptotic effects of Sesbania grandiflora leaves in human cancer cells," BioMed Research International, vol. 2014, Article ID 474953, 11 pages, 2014.

[44] L. Feng, X.-B. Jia, J. Jiang et al., "Combination of active components enhances the efficacy of Prunella in prevention and treatment of lung cancer," Molecules, vol. 15, no. 11, pp. 78937906, 2010.
[45] B. Y. Kim, J. Lee, S. J. Park, O. S. Bang, and N. S. Kim, "Gene expression profile of the A549 human non-small cell lung carcinoma cell line following treatment with the seeds of descurainia sophia, a potential anticancer drug," Evidence-based Complementary and Alternative Medicine, vol. 2013, Article ID 584604, 13 pages, 2013.

[46] J. W. Hwang, J. H. Oh, H.-S. Yoo et al., "Mountain ginseng extract exhibits anti-lung cancer activity by inhibiting the nuclear translocation of NF- $\kappa \mathrm{B}$," The American Journal of Chinese Medicine, vol. 40, no. 1, pp. 187-202, 2012.

[47] E.-C. Kim, J.-K. Min, T.-Y. Kim et al., "[6]-Gingerol, a pungent ingredient of ginger, inhibits angiogenesis in vitro and in vivo," Biochemical and Biophysical Research Communications, vol. 335, no. 2, pp. 300-308, 2005.

[48] D. R. Avisetti, K. S. Babu, and S. V. Kalivendi, "Activation of p38/JNK pathway is responsible for embelin induced apoptosis in lung cancer cells: transitional role of reactive oxygen species," PLoS ONE, vol. 9, no. 1, Article ID e87050, 2014.

[49] S. Mohan, S. I. Abdelwahab, S. C. Cheah et al., "Apoptosis effect of girinimbine isolated from Murraya koenigii on lung cancer cells in vitro," Evidence-based Complementary and Alternative Medicine, vol. 2013, Article ID 689865, 12 pages, 2013.

[50] Z.-H. Fei, K. Wu, Y.-L. Chen, B. Wang, S.-R. Zhang, and S.-L. $\mathrm{Ma}$, "Capilliposide isolated from Lysimachia capillipes Hemsl. Induces ROS generation, cell cycle arrest, and apoptosis in human nonsmall cell lung cancer cell lines," Evidence-Based Complementary and Alternative Medicine, vol. 2014, Article ID 497456, 11 pages, 2014.

[51] J. Gao, H. Zhao, P. J. Hylands, and O. Corcoran, "Secondary metabolite mapping identifies Scutellaria inhibitors of human lung cancer cells," Journal of Pharmaceutical and Biomedical Analysis, vol. 53, no. 3, pp. 723-728, 2010.

[52] J. Hung, C. Wen, Y. Hsu et al., "Subamolide a induces mitotic catastrophe accompanied by apoptosis in human lung cancer cells," Evidence-Based Complementary and Alternative Medicine, vol. 2013, Article ID 828143, 15 pages, 2013.

[53] C.-S. Lin, Y.-J. Chen, J. J. W. Chen et al., "Terpinen-4-ol induces apoptosis in human nonsmall cell lung cancer in vitro and in vivo," Evidence-Based Complementary and Alternative Medicine, vol. 2012, Article ID 818261, 13 pages, 2012.

[54] A. Cheng, W. Chang, Y. Cheng, K. Chen, and T. Chang, "The effects of davallic acid from Davallia divaricata blume on apoptosis induction in A549 lung cancer cells," Molecules, vol. 17, no. 11, pp. 12938-12949, 2012.

[55] W. Zheng, X. Gao, C. Chen, and R. Tan, “Total flavonoids of Daphne genkwa root significantly inhibit the growth and metastasis of Lewis lung carcinoma in C57BL6 mice," International Immunopharmacology, vol. 7, no. 2, pp. 117-127, 2007.

[56] W. Li, Y. Yang, Z. Ouyang et al., "Xiao-Ai-Ping, a TCM injection, enhances the antigrowth effects of cisplatin on lewis lung cancer cells through promoting the infiltration and function of $\mathrm{CD}^{+} \mathrm{T}$ Lymphocytes," Evidence-Based Complementary and Alternative Medicine, vol. 2013, Article ID 879512, 9 pages, 2013.

[57] S.-Y. Han, H.-R. Ding, W. Zhao, F. Teng, and P.-P. Li, "Enhancement of gefitinib-induced growth inhibition by Marsdenia tenacissima extract in non-small cell lung cancer cells expressing wild or mutant EGFR," BMC Complementary and Alternative Medicine, vol. 14, article 165, 2014.

[58] A. I. Calderón, C. Terreaux, M. P. Gupta, and K. Hostettmann, "In vitro cytotoxicity of 11 Panamanian plants," Fitoterapia, vol. 74, no. 4, pp. 378-383, 2003. 
[59] K. Pinmai, S. Chunlaratthanabhorn, C. Ngamkitidechakul, N. Soonthornchareon, and C. Hahnvajanawong, "Synergistic growth inhibitory effects of Phyllanthus emblica and Terminalia bellerica extracts with conventional cytotoxic agents: doxorubicin and cisplatin against human hepatocellular carcinoma and lung cancer cells," World Journal of Gastroenterology, vol. 14, no. 10, pp. 1491-1497, 2008.

[60] S. Liu, X.-M. Wang, and G.-W. Yang, "Action mechanism of fuzheng fangai pill combined with cyclophosphamide on tumor metastasis and growth," Evidence-Based Complementary and Alternative Medicine, vol. 2014, Article ID 494528, 11 pages, 2014.

[61] X. Xu, Y. Zhang, D. Qu et al., "Combined anticancer activity of osthole and cisplatin in NCI-H460 lung cancer cells in vitro," Experimental and Therapeutic Medicine, vol. 5, no. 3, pp. 707710, 2013.

[62] M. McCulloch, C. See, X. Shu et al., "Astragalus-based Chinese herbs and platinum-based chemotherapy for advanced nonsmall-cell lung cancer: meta-analysis of randomized trials," Journal of Clinical Oncology, vol. 24, no. 3, pp. 419-430, 2006.

[63] Y. Z. Chen, Z. D. Li, F. Gao, Y. Zhang, H. Sun, and P. P. $\mathrm{Li}$, "Effects of combined Chinese drugs and chemotherapy in treating advanced non-small cell lung cancer," Chinese Journal of Integrative Medicine, vol. 15, no. 6, pp. 415-419, 2009.

[64] A. K. Babu, A. Templeton, A. Munshi, and R. Ramesh, "Nanoparticle-based drug delivery for therapy of lung cancer: progress and challenges," Progress and Challenges, vol. 2013, Article ID 863951, 11 pages, 2013.

[65] "Liposomal cisplatin ( Nanoplatin ) for advanced non-small cell lung cancer-first line (2012)," http://www.hsc.nihr.ac.uk/ topics/liposomal-cisplatin-nanoplatin-for-advanced-non-sm/.

[66] M. Chen, J. Zhang, S. Yu et al., "Anti-lung-cancer activity and liposome-based delivery systems of $\beta$-elemene," Evidence-Based Complementary and Alternative Medicine, vol. 2012, Article ID 259523, 5 pages, 2012.

[67] A. R. Khuda-Bukhsh, S. Paul, S. S. Bhattacharyya, and N. Boujedaini, "Anticancer potentials of root extract of Polygala senega and its PLGA nanoparticles-encapsulated form," Evidence-Based Complementary and Alternative Medicine, vol. 2011, Article ID 517204, 13 pages, 2011.

[68] J. S. Silva, M. D. Moura, R. A. G. Oliveira, M. F. F. Diniz, and J. M. Barbosa-Filho, "Natural product inhibitors of ovarian neoplasia," Phytomedicine, vol. 10, no. 2-3, pp. 221-232, 2003.

[69] J. E. R. Honório Júnior, P. M. Soares, C. L. Melo et al., "Atividade farmacológica da monocrotalina isolada de plantas do gênero Crotalaria," Revista Brasileira de Farmacognosia, vol. 20, no. 3, pp. 453-458, 2010.

[70] R. N. Almeida, D. S. Navarro, and J. M. Barbosa-Filho, "Plants with central analgesic activity," Phytomedicine, vol. 8, no. 4, pp. 310-322, 2001.

[71] H. S. Falcão, J. A. Leite, J. M. Barbosa-Filho et al., "Gastric and duodenal antiulcer activity of alkaloids: a review," Molecules, vol. 13, no. 12, pp. 3198-3223, 2008.

[72] N. Z. T. de Jesus, H. de Souza Falcão, I. F. Gomes et al., "Tannins, peptic ulcers and related mechanisms," International Journal of Molecular Sciences, vol. 13, no. 3, pp. 3203-3228, 2012.

[73] L. G. Rocha, J. R. G. S. Almeida, R. O. Macêdo, and J. M. Barbosa-Filho, "A review of natural products with antileishmanial activity," Phytomedicine, vol. 12, no. 6-7, pp. 514-535, 2005.

[74] G. R. M. Lima, C. A. Montenegro, C. L. F. Almeida, P. F. Athayde-Filho, J. M. Barbosa-Filho, and L. M. Batista,
"Database survey of anti-inflammatory plants in South America: a review," International Journal of Molecular Sciences, vol. 12, no. 4, pp. 2692-2749, 2011.

[75] H. S. Falcão, I. R. Mariath, M. F. F. M. Diniz, L. M. Batista, and J. M. Barbosa-Filho, "Plants of the American continent with antiulcer activity," Phytomedicine, vol. 15, no. 1-2, pp. 132-146, 2008.

[76] K. S. L. de Mota, G. E. N. Dias, M. E. F. Pinto et al., "Flavonoids with gastroprotective activity," Molecules, vol. 14, no. 3, pp. 9791012, 2009.

[77] A. L. Souto, J. F. Tavares, M. S. da Silva, M. F. F. M. de Diniz, P. F. de Athayde-Filho, and J. M. Barbosa Filho, "Anti-inflammatory activity of alkaloids: an update from 2000 to 2010," Molecules, vol. 16, no. 10, pp. 8515-8534, 2011.

[78] M. D. F. Agra, K. N. Silva, I. J. L. D. Basílio, P. F. De Freitas, and J. M. Barbosa-Filho, "Survey of medicinal plants used in the region Northeast of Brazil," Brazilian Journal of Pharmacognosy, vol. 18, no. 3, pp. 472-508, 2008.

[79] F. L. Silva, D. C. H. Fischer, J. F. Tavares, M. S. Silva, P. F. De Athayde-Filho, and J. M. Barbosa-Filho, "Compilation of secondary metabolites from Bidens pilosa L," Molecules, vol. 16, no. 2, pp. 1070-1102, 2011.

[80] L. J. Quintans Jr., J. R. G. S. Almeida, J. T. Lima et al., "Plants with anticonvulsant properties-a review," Brazilian Journal of Pharmacognosy, vol. 18, pp. 798-819, 2008.

[81] F. C. F. Sousa, C. T. V. Melo, M. C. O. Citó et al., "Plantas medicinais e seus constituintes bioativos: Uma revisão da bioatividade e potenciais benefícios nos distúrbios da ansiedade em modelos animais," Revista Brasileira de Farmacognosia, vol. 18, no. 4, pp. 642-654, 2008.

[82] J. R. Filho, H. de Sousa Falcão, L. M. Batista, J. M. B. Filho, and M. R. Piuvezam, "Effects of plant extracts on HIV-1 protease," Current HIV Research, vol. 8, no. 7, pp. 531-544, 2010.

[83] J. M. Barbosa-Filho, A. A. Alencar, X. P. Nunes et al., "Sources of alpha-, beta-, gamma-, delta- and epsilon-carotenes: a twentieth century review," Brazilian Journal of Pharmacognosy, vol. 18, no. 1, pp. 135-154, 2008.

[84] C. L. F. de Almeida, H. D. S. Falcão, G. R. D. M. Lima et al., "Bioactivities from marine algae of the genus Gracilaria," International Journal of Molecular Sciences, vol. 12, no. 7, pp. 4550-4573, 2011.

[85] V. F. Veiga Junior, A. C. Pinto, and M. A. M. Maciel, "Plantas medicinais: segura?” Química Nova, vol. 28, pp. 519-528, 2005.

[86] Y. S. Yun, Y. S. Lee, S. K. Jo, and I. S. Jung, "Inhibition of autochthonous tumor by ethanol insoluble fraction from Panax ginseng as an immunomodulator," Planta Medica, vol. 59, no. 6, pp. 521-524, 1993.

[87] S. M. Kupchan, R. J. Hemingway, P. Coggon, A. T. McPhail, and G. A. Sim, "Crotepoxide, a novel cyclohexane diepoxide tumor inhibitor from Croton macrostachys," Journal of the American Chemical Society, vol. 90, no. 11, pp. 2982-2983, 1968.

[88] Y. Kimura, K. Baba, and H. Okuda, "Inhibitory effects of active substances isolated from Cassia garrettiana heartwood on tumor growth and lung metastasis in lewis lung carcinomabearing mice (Part 1)," Anticancer Research, vol. 20, no. 5, pp. 2899-2906, 2000.

[89] Y. Kimura, K. Baba, and H. Okuda, "Inhibitory effects of active substances isolated from Cassia garrettiana heartwood on tumor growth and lung metastasis in Lewis lung carcinomabearing mice (part 2)," Anticancer Research, vol. 20, no. 5, pp. 2923-2930, 2000. 
[90] E. Furusawa and S. Furusawa, "Anticancer activity of a natural product, viva-natural, extracted from Undaria pinnantifida on intraperitoneally implanted Lewis lung carcinoma," Oncology, vol. 42, no. 6, pp. 364-369, 1985.

[91] E. Furusawa and S. Furusawa, "Anticancer potential of VivaNatural, a dietary seaweed extract, on Lewis lung carcinoma in comparison with chemical immunomodulators and on cyclosporine-accelerated AKR leukemia," Oncology, vol. 46, no. 5, pp. 343-349, 1989.

[92] E. Furusawa and S. Furusawa, "Antitumor potential of low-dose chemotherapy manifested in combination with immunotherapy of viva-natural, a dietary seaweed extract, on Lewis lung carcinoma," Cancer Letters, vol. 50, no. 1, pp. 71-78, 1990.

[93] Z. Q. Wang, Y. M. Chen, G. W. Jin, and S. S. Lin, "Combined therapy of brain metastasis in lung cancer," Chinese Journal of Integrated Traditional and Western Medicine, vol. 1, pp. 36-38, 1995.

[94] S. C. Wu, "Preoperative intravenous drip of an anti-tumor Chinese herb preparation, Brucea javanica oil emulsion (Ya Dan Zi Emulsion) for lung cancer," Shang-Hai I Hsueh, vol. 14, pp. 273-275, 1991.

[95] S. M. Kupchan and H. L. Kopperman, "l-Usnic acid: tumor inhibitor isolated from lichens," Experientia, vol. 31, no. 6, p. 625, 1975.

[96] T. A. Khwaja, C. B. Dias, and S. Pentecost, "Recent studies on the anticancer activities of mistletoe (Viscum album) and its alkaloids," Oncology, vol. 43, no. 1, pp. 42-50, 1986.

[97] N. Zarkovic, S. Mang, T. Vukovic et al., "An overview on anticancer activities of the Viscum Album extract Isorel," Cancer Biotherapy and Radiopharmaceuticals, vol. 16, no. 1, pp. 55-62, 2001.

[98] J. M. Braun, H. L. Ko, J. M. Schierholz, D. Weir, C. C. Blackwell, and J. Beuth, "Application of standardized mistletoe extracts augment immune response and down regulates metastatic organ colonization in murine models," Cancer Letters, vol. 170, no. 1, pp. 25-31, 2001.

[99] G. Bar-Sela, M. Wollner, L. Hammer, A. Agbarya, E. Dudnik, and N. Haim, "Mistletoe as complementary treatment in patients with advanced non-small-cell lung cancer treated with carboplatin-based combinations: a randomised phase II study," European Journal of Cancer, vol. 49, no. 5, pp. 1058-1064, 2013.

[100] G. W. Bradley and A. Clover, "Apparent response of small cell lung cancer to an extract of mistletoe and homoeopathic treatment," Thorax, vol. 44, no. 12, pp. 1047-1048, 1989.

[101] K. Noda, N. Ohno, K. Tanaka et al., "A new type of biological response modifier from Chlorella vulgaris which needs protein moiety to show an antitumour activity," Phytotherapy Research, vol. 12, no. 5, pp. 309-319, 1998.

[102] S. B. Han, C. W. Lee, Y. J. Jeon et al., "The inhibitory effect of polysaccharides isolated from Phellinus linteus on tumor growth and metastasis," Immunopharmacology, vol. 41, no. 2, pp. 157164, 1999.

[103] E. Kyo, N. Uda, A. Suzuki et al., "Immunomodulation and antitumor activities of aged garlic extract," Phytomedicine, vol. 5, no. 4, pp. 259-267, 1998.

[104] E. Kyo, N. Uda, S. Kasuga, Y. Itakura, and H. Sumiyoshi, "Garlic as an immunostimulant," in Immunomodulatory Agents from Plants, H. Wagner, Ed., pp. 273-288, Birkhäuser, Basel, Switzerland, 1999.

[105] A. Staniszewski, B. Slesak, J. Kolodziej, A. HarlozinskaSzmyrka, and J. W. Nowicky, "Lymphocyte subsets in patients with lung cancer treated with thiophosphoric acid alkaloid derivatives from Chelidonium majus L. (Ukrain)," Drugs under Experimental and Clinical Research, vol. 18, no. 63, pp. 63-67, 1992.

[106] S. S. M. Kumara and B. T. K. Huat, "Extraction, isolation and characterisation of antitumor principle, $\alpha$-hederin, from the seeds of Nigella sativa," Planta Medica, vol. 67, no. 1, pp. 29-32, 2001.

[107] School of Hygiene, Report of Treatment for Lung Carcinoma Using Manshanxiang Complex, In-house Publication, Yuxi District, China, 1980.

[108] G-H. Xu, Z. Yang, G-H. Zhou, and T-H. He, Chinese Traditional and Herbal Drugs, vol. 15, no. 3, p. 432, 1984.

[109] J. Liu, M. Huang, and Y. Tao, "Anwuweizonic acid and manwuweizic acid, the putative anticancer active principle of Schisandra propinqua," Canadian Journal of Chemistry, vol. 66, no. 3, pp. 414-415, 1988.

[110] L. Mishra, B. B. Singh, and S. Dagenais, "Scientific basis for the therapeutic use of Withania somnifera (ashwagandha): a review, Alternative Medicine Review, vol. 5, no. 4, pp. 334-346, 2000.

[111] N. Singh, P. Verma, B. R. Pandey, and M. Gilca, "Role of withania somnifera in prevention and treatment of cancer: an overview," International Journal of Pharmaceutical Sciences and Drug Research, vol. 3, no. 4, pp. 274-279, 2011.

[112] M. D. Brown, "Green tea (Camellia sinensis) extract and its possible role in the prevention of cancer," Alternative Medicine Review, vol. 4, no. 5, pp. 360-370, 1999.

[113] J.-M. Yuan, "Cancer prevention by green tea: evidence from epidemiologic studies," The American Journal of Clinical Nutrition, vol. 98, no. 6, pp. 1676S-1781S, 2013.

[114] G. Yang, Z. Wang, S. Kim et al., "Characterization of early pulmonary hyperproliferation and tumor progression and their inhibition by black tea in a 4-(methylnitrosamino)-1-(3pyridyl)-1-butanone-induced lung tumorigenesis model with A/J mice," Cancer Research, vol. 57, no. 10, pp. 1889-1894, 1997.

[115] H. Saitoh, W. Feng, T. Matsuzawa, and T. Ikekawa, "Antitumor activity of Hypsizigus marmoreus. II. preventive effect against lung metastasis of Lewis lung carcinoma," Yakugaku Zasshi, vol. 117, no. 12, pp. 1006-1010, 1997.

[116] E. Furusawa, S. C. Chou, S. Furusawa, A. Hirazumi, and Y. Dang, "Antitumour activity of Ganoderma lucidum, an edible mushroom, on intraperitoneally implanted Lewis lung carcinoma in synergenic mice," Phytotherapy Research, vol. 6, no. 6, pp. 300-304, 1992.

[117] Y. Kimura, M. Taniguchi, and K. Baba, "Antitumor and antimetastatic effects on liver of triterpenoid fractions of Ganoderma lucidum: mechanism of action and isolation of an active substance," Anticancer Research, vol. 22, no. 6A, pp. 3309-3318, 2002.

[118] Y. Yu, H. Kuo, H. Hsieh et al., "Ganoderma tsugae induces $S$ phase arrest and apoptosis in doxorubicin-resistant lung adenocarcinoma $\mathrm{H} 23 / 0.3$ cells via modulation of the PI3K/Akt signaling pathway," Evidence-Based Complementary and Alternative Medicine, vol. 2012, Article ID 371286, 13 pages, 2012.

[119] S. Curic, Z. Tadic, I. Valpotic, D. Sulimanovic, and I. Basic, "The effect of bee venom on tumor growth and metastasis formation of mammary carcinoma in CBA mice," Veterinarski Arhiv, vol. 62, pp. S31-S35, 1992.

[120] B. Sokoloff, "The oncostatic and oncolytic factors present in certain plants.," Oncology, vol. 22, no. 1, pp. 49-60, 1968. 
[121] M. P. Chitnis, K. G. Bhatia, M. K. Phatak, and K. V. K. Rao, "Anti-tumour activity of the extract of Semecarpus anacardium L. nuts in experimental tumour models," Indian Journal of Experimental Biology, vol. 18, no. 1, pp. 6-8, 1980.

[122] M. P. Chitnis, K. G. Bhatia, and M. K. Phatak, "Anti-tumour activity of the methanol extract Ervatamia heyneana (NSC B668619)," Indian Journal of Experimental Biology, vol. 17, no. 2, p. 212, 1979.

[123] F. K. Dzhioev, "Influence of extract of eleutherococcus on urethane-induced lung adenomas in mice," Voprosy Onkologii, vol. 11, no. 9, pp. 51-54, 1965.

[124] T. K. Yun, Y. S. Yun, and I. W. Han, "An experimental study on tumor inhibitory effect of red ginseng in mice and rats exposed to various chemical carcinogens," in Proceedings of the $3 \mathrm{rd}$ International Ginseng Symposium, pp. 87-113, Seoul, Republic of Korea, 1980.

[125] M. L. Dhar, M. M. Dhar, B. N. Dhawan, B. N. Mehrotra, and C. Ray, "Screening of Indian plants for biological activity: I.," Indian Journal of Experimental Biology, vol. 6, no. 4, pp. 232$247,1968$.

[126] G. R. Ickes, H. H. Fong, P. L. Schiff Jr., R. E. Perdue Jr., and N. R. Farnsworth, "Antitumor activity and preliminary phytochemical examination of Tagetes minuta (Compositae)," Journal of Pharmaceutical Sciences, vol. 62, no. 6, pp. 1009-1011, 1973.

[127] S. M. Kupchan, Y. Komoda, W. A. Court et al., "Tumor inhibitors. LXXIII. Maytansine, a novel antileukemic ansa macralide from Maytenus ovatus," Journal of the American Chemical Society, vol. 94, no. 4, pp. 1354-1356, 1972.

[128] N. R. Farnsworth, H. Wagner, L. Hörhammer, H. P. Hörrhammer, and H. H. S. Fong, "Euphorbia esula L. (Euphorbiaceae). I. Preliminary phytochemical and biological evaluation," Journal of Pharmaceutical Sciences, vol. 57, no. 6, pp. 933-939, 1968.

[129] S. M. Kupchan, I. Uchida, A. R. Branfman, R. G. Dailey Jr., and B. Y. Fei, "Antileukemic principles isolated from Euphorbiaceae plants," Science, vol. 191, no. 4227, pp. 571-572, 1976.

[130] J. Shentu, P. Wei, A. Wang et al., "A study of the antitumor effect of Euphorbia fischeriana steud on mice with induced tumor," Chinese Journal of Integrated Traditional and Western Medicine, vol. 4, pp. 46-47, 1984.

[131] A. J. Charlson, "Antineoplastic constituents of some Southern African plants," Journal of Ethnopharmacology, vol. 2, no. 4, pp. 323-335, 1980.

[132] S. M. Kupchan, C. W. Sigel, M. J. Matz, J. A. S. Renauld, R. C. Haltiwanger, and R. F. Bryan, "Jatrophone, a novel macrocyclic diterpenoid tumor inhibitor from Jatropha gossypiifolia [16]," Journal of the American Chemical Society, vol. 92, no. 14, pp. 4476-4477, 1970.

[133] R. E. Perdue Jr., "KB cell culture: I. Role in discovery of antitumor agents from higher plants," Journal of Natural Products, vol. 45, no. 4, pp. 418-426, 1982.

[134] C. Yang, W. Lu, and J. Niu, "Studies on the antitumor action of xiangshenboheyou (a mixture composed of Pelargonium graveolens and Sophora flavescens and other herbs)," Chung Ts'ao Yao, vol. 14, no. 9, pp. 409-410, 1983.

[135] S. Lee, Y. Wei, C. Chen, S. Wang, and K. Chen, "Antitumor effects of Ganoderma lucidum," The Journal of Chinese Medicine, vol. 6, no. 4, pp. 1-12, 1995.

[136] B. Min, H. Lee, K. Bae, J. Gao, N. Nakamura, and M. Hattori, "Antitumor activity of cultured mycelia of Ganoderma lucidum," Natural Product Sciences, vol. 8, no. 2, pp. 52-55, 2002.
[137] A. M. Burger, U. Mengs, J. B. Schüler, and H. Fiebig, "Anticancer activity of an aqueous mistletoe extract (AME) in syngeneic murine tumor models," Anticancer Research, vol. 21, no. 3B, pp. 1965-1968, 2001.

[138] Y. Cheng, S. Lee, H. Harn, H. Huang, and W. Chang, "The extract of Hibiscus syriacus inducing apoptosis by activating p53 and AIF in human lung cancer cells," The American Journal of Chinese Medicine, vol. 36, no. 1, pp. 171-184, 2008.

[139] A. Ulubelen and J. R. Cole, "Proteinaceous antitumor substances from plants Mirabilis multiflora," Journal of Pharmaceutical Sciences, vol. 55, no. 12, pp. 1368-1370, 1966.

[140] R. Perdue Jr., R. Smith, M. Wall, J. Hartwell, and B. Abbott, "Camptotheca acuminata (Nyssaceae). Source of camptothecin, an antileukemic alkaloid," Technical Bulletin 1415, ARS, USDA, Washington, DC, USA, 1970.

[141] G. J. Persinos, M. W. Quimby, A. R. Mott et al., "Studies on Nigerian plants: III. Biological and phytochemical screening of Lophira lanceolata, and the isolation of benzamide," Planta Medica, vol. 15, no. 4, pp. 361-365, 1967.

[142] J. J. Barchi Jr., R. E. Moore, and G. M. L. Patterson, "Acutiphycin and 20,21-didehydroacutiphycin, new antineoplastic agents from the cyanophyte Oscillatoria acutissima," Journal of the American Chemical Society, vol. 106, no. 26, pp. 8193-8197, 1984.

[143] Anonymous, "Polysaccharide neoplasm inhibitors from mollusks," Patent-Japan Kokai Tokkyo Koho-82 18,620, Patent Microbiochemical Research Found, Tokyo, Japan, 1982.

[144] A. Hirazumi, E. Furusawa, S. C. Chou, and Y. Hokama, "Immunomodulation contributes to the anticancer activity of Morinda citrifolia (Noni) fruit juice," Proceedings of the Western Pharmacology Society, vol. 39, pp. 7-9, 1996.

[145] J. Loder and G. Russell, "Tumor inhibitory plants. The alkaloids of Bruguiera sexangula and Bruguiera exaristata (Rhizophoraceae)," Australian Journal of Chemistry, vol. 22, no. 6, pp. 1271-1275, 1969.

[146] B. Hu, N. Yang, W. Liu, H. Sha, and D. Yu, "Estimation of integrations of various functional groups of Brucea javanica (L.) Merr. Oil," Bopuxue Zazhi, vol. 8, pp. 433-440, 1991.

[147] S. Y. Su, "Treatment of lung cancer with brain metastasis using an intravenous drip of a $10 \%$ emulsion of Brucea javanica seminal oil," Chinese Journal of Integrated Traditional and Western Medicine, vol. 5, no. 2, pp. 86-88, 1985.

[148] S. Singh, D. Singh, M. Gupta, N. Singh, and R. Kohli, "An experimental evaluation of antitumor activity of Withania somnifera (Ashwagandha) and Geriforte," Indian Journal of Pharmacology, vol. 11, no. 65b, 1979.

[149] Y. Jiang, J. Chen, Z. Wu, L. Lin, and S. Feng, "Inhibitory effect of tea polyphenol on mice lung cancer induced by diethylstilbestrol combined with urethane," Weisheng Dulixue Zazhi, vol. 12, pp. 7-9, 1998.

[150] H. Nanba, K. Mori, T. Toyomasu, and H. Kuroda, "Antitumor action of shiitake (Lentinus edodes) fruit bodies orally administered to mice," Chemical and Pharmaceutical Bulletin, vol. 35, no. 6, pp. 2453-2458, 1987. 


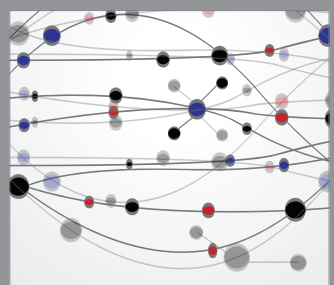

The Scientific World Journal
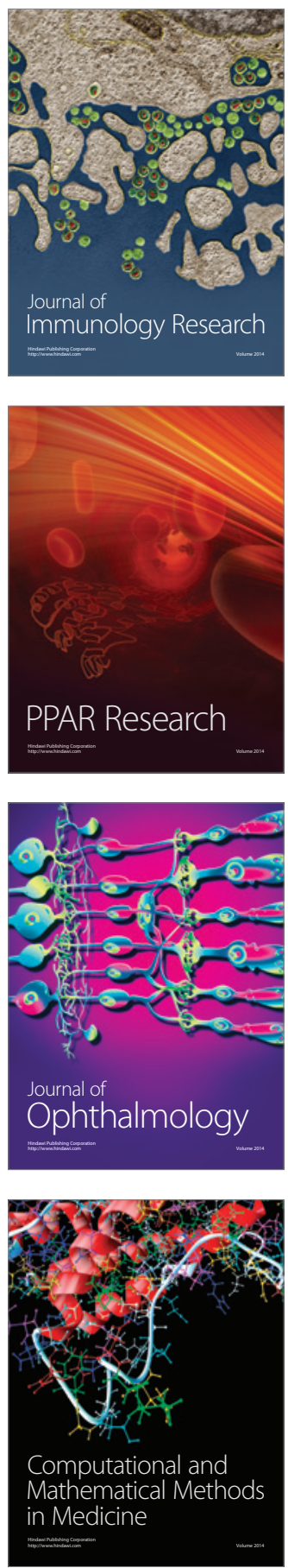

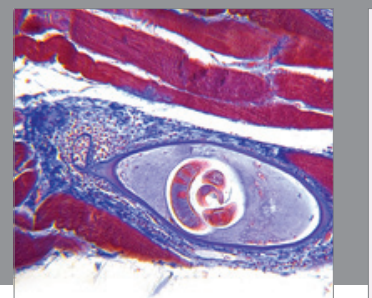

Gastroenterology

Research and Practice
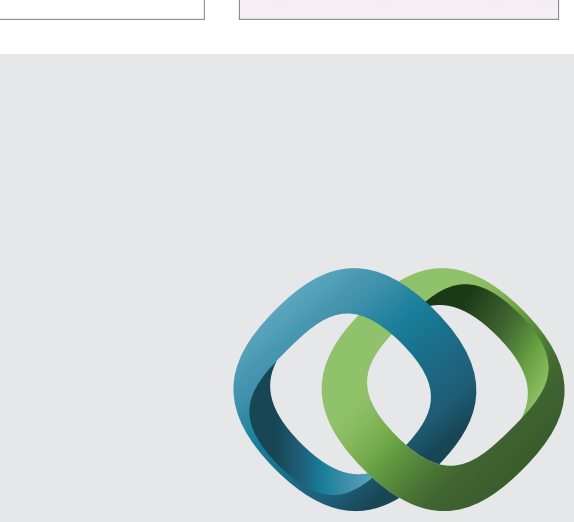

\section{Hindawi}

Submit your manuscripts at

http://www.hindawi.com
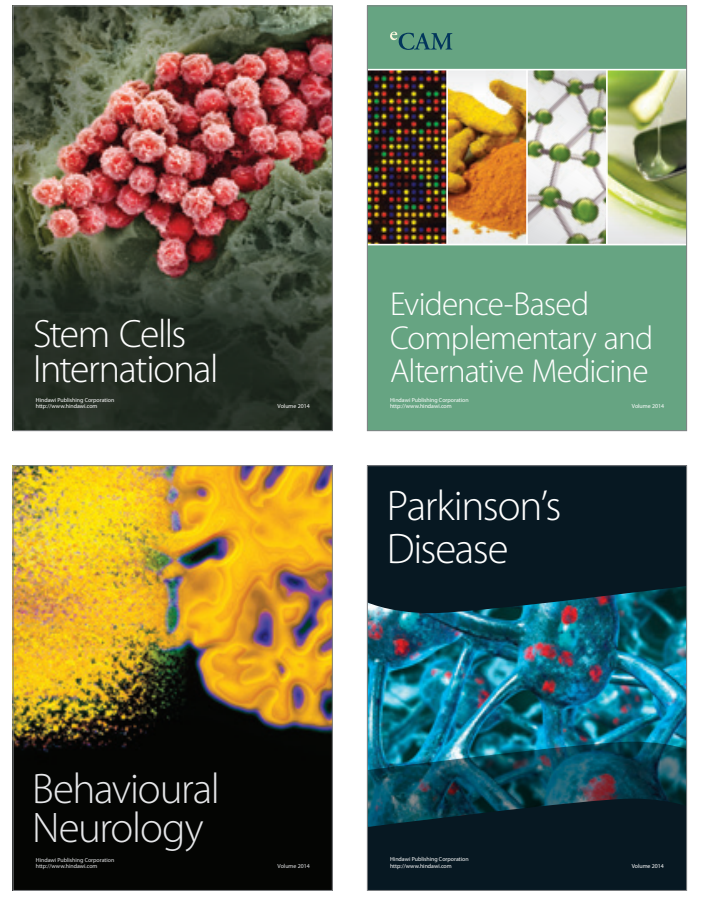
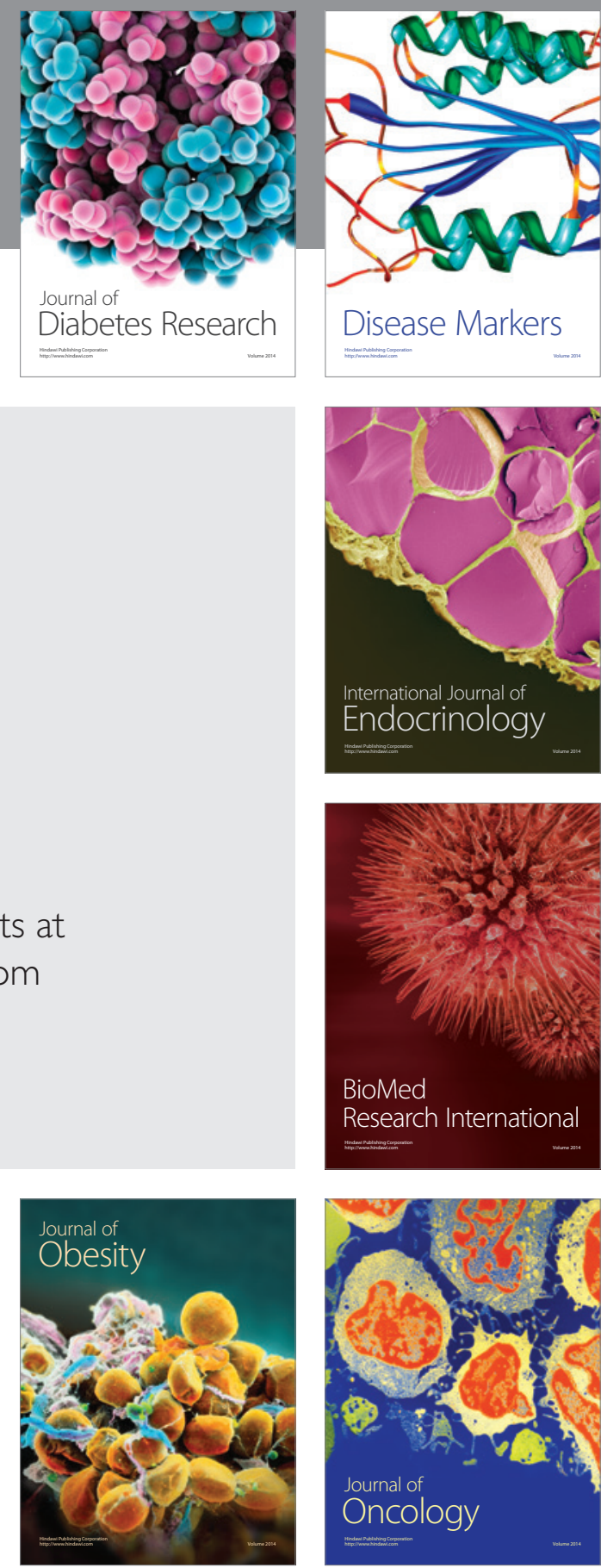

Disease Markers
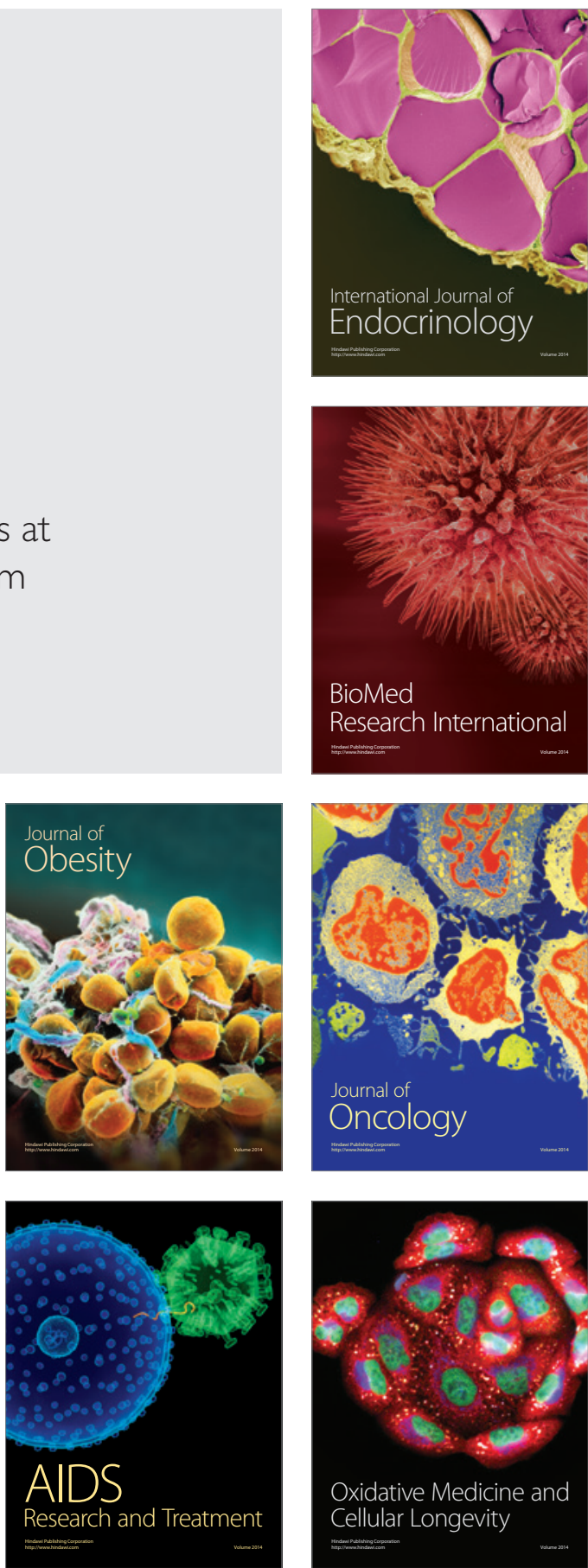